\title{
KASUS AGITASI AKIBAT PEMAKAIAN MEPHEDRONE
}

\author{
Dewa Ayu Sri Kusuma Dewi", Ni Made Widi Astuti, Pande Made Nova \\ Armita Sari, IMA Gelgel Wirasuta. \\ Departemen Toksikolgi Forensik \\ Laboratorium Toksikologi Forensik Universitas Udayana \\ Program Studi Farmasi Fakultas Matematika dan Ilmu Pengetahuan Alam \\ Universitas Udayana Badung Bali Indonesia \\ *email : srikusumadewi946@yahoo.com
}

\begin{abstract}
Mephedrone or 4-Methylmethcathinone is one type of NPS (New Psychoactive Substance) which is included in the katinon derivative. Mephedrone has been banned in Indonesia and in other countries such as the Netherlands. Mephedrone is used as a recrerational drug that can increase enthusiasm for its users. Misuse of mephedrone can cause toxicity to death for its users. In reviewing this article we will summarize the cases of mephedrone abuse in Indonesia, the pathway for mephedrone synthesis, the pharmacological, pharmacokinetic and pharmacodynamic effects of mephedrone and forensic toxicology analysis on cases of misuse of mephedrone compounds.
\end{abstract}

Keywords: Mephedrone, forensic toxicology, toxicity.

\section{PENDAHULUAN}

Penyalahgunaan narkotika dan obat-obatan terlarang merupakan kasus yang semakin marak terjadi Indonesia maupun di mancanega. Hal tersebut seriring dengan meningkatnya angka penyalahgunaan dan jumlah pecandu narkoba secara signifikan. Berdasarkan data WHO tahun 2016 tercatat 275 juta orang di seluruh dunia dengan usia 15-64 tahun pernah menyalahgunakan narkoba setidaknya lebih dari sekali. Dampak penyalahgunaan narkoba dapat berefek terhadap kelangsungan suatu bangsa dan negara. Salah satu dampak buruk dari penyalahgunaan narkotika dan obat-obatan terlarang yaitu munculnya rasa kegelisahan atau keresahan bagi penggunannya (agitasi) [1].

Kasus agitasi (keresahan atau kegelisahan) sebagai dampak penyalahgunaan narkotika dan obatobatan terlarang sering terjadi hingga mengakibatkan perilaku menyakiti diri sendiri. Salah satu kasus agitasi sebagai dampak penyalahgunaan narkotika dan obat-obatan terlarang yaitu terjadi di Belanda, seorang pria berusia 36 tahun melukai dirinya sendiri dengan menghancurkan jendela-jendela. Meski polisi sempat memberikan tindakan resusitasi namun korban tidak tertolong dan meninggal dunia. Setelah dilakukan autopsi terlihat banyak luka yang ditemukan pada kulit superfisial, memar dan pembengkakan otak ringan namun tidak diketahui penyebab pasti kematian. Dugaan sementara, pria tersebut telah mengkonsumsi mephedrone, hal ini diperkuat dengan ditemukannya

59 Dewa Ayu Sri Kusuma Dewi,Ni Made Widi Astuti,Pande Made Nova Armita Sari, IMA Gelgel Wirasuta. Departemen Toksikolgi Forensik Laboratorium Toksikologi Forensik Universitas Udayana Program Studi Farmasi Fakultas Matematika dan Ilmu Pengetahuan Alam Universitas Udayana Badung 
barang bukti berupa 96 tablet hijau dengan logo captagon pada salah satu tablet dan lingkaran $\mathrm{R}$ pada sisi tablet lainnya [6].

$$
\text { Mephedrone merupakan }
$$
sintesis dari cathinone. Narkoba golongan kationan telah dikenal cukup lama dan peredarannya telah dilarang di Indonesia maupun negara lainnya. Narkoba golongan katinon memiliki struktur kimia dan efek yang hampir mirip dengan amfetamin. Efek samping yang berbahaya dapat muncul dari penyalahgunan narkoba golongan katinon. Narkoba golongan katinon dapat menstimulasi hingga ke ujung sistem saraf pusat sehingga dapat menimbulkan rasa menyenangkan bagi penggunanya. Karena dapat menstimulasi sistem saraf pusat, narkoba golongan ini umumnya dapat menimbulkan candu bagi penggunannya. Efek yang dihasilkan dari narkoba golongan katinon dapat berlangsung selama empat sampai enam jam. Setelah efek katinon hilang, keadaan si pengguna akan kembali normal, lemas, hingga depresi.

Katinon sintetis ditemukan dalam bentuk serbuk kristal putih atau kecoklatan dan dimasukkan ke dalam kapsul atau dapat berbentuk tablet/pil. Katinon masuk ke dalam golongan narkotika golongan I di Indonesia jika dilihat dari Undang-Undang Nomor 35 Tahun 2009 tentang Narotika [1].

\section{KASUS PENGGUNAAN MEPHEDRONE DI INDONESIA}

Jumlah penyalahgunaan narkoba di Indonesia mencapai 1,77\% atau sekitar 3.367.154 orang yang menyalahgunakan narkoba dalam satu tahun terakhir. Penyalahguna tersebut rata-rata berada pada usia 10 hingga 59 tahun. Data tersebut diperoleh dari hasil penelitian Badan Narkotika Nasional Indonesia (BNN) yang bekerjasama dengan Pusat Penelitian Kesehatan Universitas Indonesia mengenai survey nasional penyalahgunaan narkoba. Mephedrone digolongkan ke dalam NPS (New Psychoactive Substance) [7].

Di Indonesia, tercatat bahwa mephedrone merupkan salah satu dari 53 jenis NPS yang teridentifikasi Indonesia. Total kasus penyalahgunaan NPS di Indonesia yaitu mencapai 37 kasus dengan rincian kasus yang ditemukan oleh POLRI sebanyak 26 kasus dan 11 kasus lainnya ditemukan oleh BNN [2]. Salah satu kasus penyalahgunaan NPS jenis mephedrone yang ramai diberitakan di Indonesia yaitu adanya penangkapan salah satu aktor Indonesia yang diketahui memiliki NPS jenis mephedrone. Kasus tersebut terungkap pada awal tahun 2013. Namun, berdasarkan data DAINP BNN pada tahun 2018 triwulan pertama dan kedua tidak ditemukan adanya kasus penyalahgunaan NPS jenis mephedrone di Indonesia [7].

\section{JALUR SINTESA MEPHEDRON}

Mephedrone berupa bubuk kristal putih dengan warna kuning muda, dengan bau yang khas. Mephedrone pertama kali disintesis pada tahun 1929 [4]. Jalur utama yang digunakan untuk sintesis mephedrone relatif lebih mudah dan proses sintesis mephedrone hampir

60 Dewa Ayu Sri Kusuma Dewi,Ni Made Widi Astuti,Pande Made Nova Armita Sari, IMA Gelgel Wirasuta. Departemen Toksikolgi Forensik Laboratorium Toksikologi Forensik Universitas Udayana Program Studi Farmasi Fakultas Matematika dan Ilmu Pengetahuan Alam Universitas Udayana Badung 
mirip dengan untuk sintesis MDMA dan amphetamine. Jalur sintesis ini melibatkan alpha-bromination yang merupakan dari precursor awal dari 4metilpropiofenon, diikuti oleh reaksi dari 4-metil-2-bromopropiophenone yang dihasilkan dengan metilamin hidroklorida dan trietilamin. Reaksi sintesa mephedrone diakhiri dengan terbentuknya gas atau cairan hydrogen klorida dan garam hidroklorida yang dihasilkan kemudian mengalami rekristalisasi [3], [5]. Jalur sintesis mephedrone lainya dapat melibatkan reakasi oksidasi yang tersubstitusi dengan analog ephedrine (4-methylephedrine) dengan kalium permanganate atau kalium dikromat dalam asam sulfat encer [4]. Jalur sintesis mephedrone ditunjukkan pada gambar 1 .

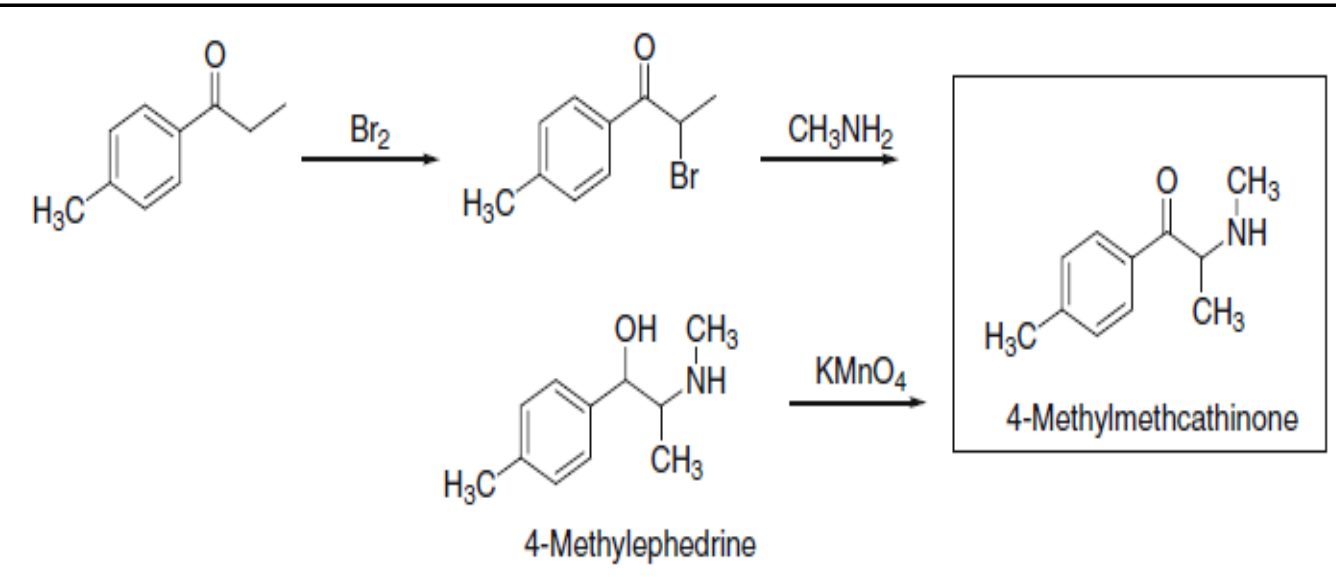

Gambar 1. Jalur sintesis mephedrone [8]

\section{EFEK FARMAKOLOGI DAN FARMAKOKINETIK}

Mephedrone

merupakan turunan senyawa katinon yang memiliki struktur kimia hamper mirip dengan amfetamin. Obat-obat golongan katinon, termasuk mephedrone merupakan zat stimulant untuk sistem saraf pusat yang akan membuat penggunanya menjadi lebih senang dan bersemangat. Efek merugikan mephedrone dalam penggunaan jangka panjang yaitu diantaranya: meningkatkan tekanan darah hingga memicu munculnya penyakit stroke, depresi, anoreksia, susah tidur, berhalusinasi, gangguan irama jantung dan gangguan psikotik. Senyawa golongan katinon dapat meningkatkan kadar neurotransmitter dopamine. Peningkatan kadar neurotransmitter dopamine dapat menimbulkan rasa gembira dan lebih bertenaga, serta meningkatkan kadar norepinefrin yang memicu peningkatan detak jantung dan tekanan darah [1].

61 Dewa Ayu Sri Kusuma Dewi,Ni Made Widi Astuti,Pande Made Nova Armita Sari, IMA Gelgel Wirasuta. Departemen Toksikolgi Forensik Laboratorium Toksikologi Forensik Universitas Udayana Program Studi Farmasi Fakultas Matematika dan Ilmu Pengetahuan Alam Universitas Udayana Badung Bali Indonesia 
Absorpsi mephedrone tergantung pada rute pemberian yang digunakan, munculnya efek yang diinginkan dari mephedrone biasanya terjadi dalam beberapa menit setelah injeksi intravena dan efek mephedrone akan muncul dalam 1545 menit setelah pemberian secara oral. Efek yang ditimbulkan oleh mephedrone dapat tertunda jika diberikan secara oral dan dikonsumsi setelah makan. Hal tersebut menunjukkan bahwa absorbsi mephedrone akan tertunda dengan adanya makanan. Durasi efek yang diinginkan dari mephedrone dapat bertahan 2-3 jam setalah pemberian secara oral dan durasi efek yang diinginkan dapat bertahan 15-30 menit setelah injeksi intravena. Salah satu penelitian mencoba menentukan metabolit mephedrone dan jalur potensial yang terlibat dalam metabolisme mephedrone dengan menggunakan hewan uji tikus. Hewan uji diberikan $20 \mathrm{mg} / \mathrm{kg}$ dosis mephedrone secara oral melalui intubasi lambung kemudian urin tikus dikumpulkan selama 24 jam. Total urin yang diperoleh dianalisis dan terdeteksi adanya metabolit mephedrone yaitu mephedrone, normephedrone, nordihydromephedrone, hydroxytolyl mephedrone, dan nor-hydroxytolyl mephedrone [4].

Uji untuk model

farmakodinamik dari senyawa mephedrone belum dilakukan penelitian pada manusia ataupun hewan. Mephedrone berperan dalam inhibitor reuptake reseptor serotonin, norepinefrin dan dopamine. Efek yang diinginkan dari mepherone memiliki stimulan dan efek simpatomimetik yang hampir sama dengan MDMA dan kokain [4].

\section{ANALISIS FORENSIK \\ TOKSIKOLOGI}

Analisis toksikologi forensik umumnya dilakukan dalam beberapa tahapan yaitu penyiapan sampel, skrining tes, uji konfirmasi, dan uji determinasi. Umumnya saat dilakukan analisis toksikologi forensik, yang ditemukan tidak hanya berupa senyawa induk namun dapat juga berupa senyawa metabolit dari senyawa induk tersebut. Senyawa metabolit tersebut dapat menjadi target analisis toksikologi forensik, hal tersebut karena beberapa senyawa induk saat masuk ke sistem peredaran darah manusia dapat mengalami metabolisme menjadi senyawa metabolit [9]. Beberapa tahapan analisis toksikologi forensik tersebut diantaranya:

a. Penyiapan sampel

Jenis dan sifat biologis spesimen, sifat fisika kimia spesimen dan tujuan dilakukannya analisis toksikologi forensik merupakan beberapa hal yang perlu diperhitungkan saat akan menyiapkan sampel. Dengan mempertimbangkan hal tersebut, maka dapat ditentukan dan dirancang metode preparasi sampel, jumlah sampel yang digunakan dan metode analisis toksikologi forensik yang tepat [9].

b. Skrining tes

Skrining tes merupakan salah satu tahapan dari analisis toksikologi forensik yang dilakukan untuk mengidentifikasi golongan senyawa yang akan dianalisis [9].

c. Uji Konfirmasi

62 Dewa Ayu Sri Kusuma Dewi,Ni Made Widi Astuti,Pande Made Nova Armita Sari, IMA Gelgel Wirasuta. Departemen Toksikolgi Forensik Laboratorium Toksikologi Forensik Universitas Udayana Program Studi Farmasi Fakultas Matematika dan Ilmu Pengetahuan Alam Universitas Udayana Badung Bali Indonesia 
Uji konfirmasi dilakukan untuk menetapkan identitas analit yang dianalisis. Uji konfirmasi dapat dilakukan dengan beberapa metode diantaranya HPLC, GC-MS atau KLT-Spektrofotodensitometri. Uji konfirmasi dapat digunakan untuk menarik kesimpulan apakah seseorang telah menyalahgunakan obat terlarang atau tidak [9].

d. Uji Determinasi dan Interpretasi Hasil Analisis

Hasil dari suatu metode analisis toksikologi forensik perlu dilengkapi dengan interpretasi data oleh seorang toksikolog forensik. Golongan senyawa yang ditemukan saat skrining tes dapat dijadikan petunjuk apabila seseorang telah menyalahgunakan obat-obatan terlarang [9].

Senyawa mephedrone dapat dianalisis menggunakan beberapa metode diantaranya spektoskopi inframerah dan spektroskopi raman. Namun, penggunaan kedua metode ini hanya dapat digunakan untuk senyawa mephedrone murni. Sehingga analisis mephedrone dan metabolitnya kini dikembangkan dengan metode GC-MS ataupun HPLC-MS [4]. Analisis toksikologi forensik keberadaan mephedrone pada suatu specimen didasarkan menjadi beberapa tahapan yaitu diantaranya skrining tes, uji konfirmasi dan uji determinasi. Salah satu kasus penyalahgunaan mephedrone yang diteliti yaitu kasus yang terjadi di Belanda. Pada kasus tersebut, penyebab kematian korban diduga disebabkan karena penyalahgunaan senyawa mephedrone hingga menimbulkan agitasi pada pengguna [6]. Identifikasi mephedrone pada kasus agitasi di Belanda tersebut ditentukan menggunakan sampel darah femoralis, urin dan isi perut setelah diendapkan proteinnya menggunakan aseton. Dalam metode ini, oxazepamD5 digunakan sebagai standar internal universal. Sampel biologis sebanyak 0,25 $\mathrm{mL}$ dianalisis dengan dan tanpa penambahan standar internal (dilakukan replikasi duplo, penambahan standar internal yaitu 0,2 $\mathrm{mg} / \mathrm{L})$. Standar internal adalah senyawa yang hampir serupa, namun tidak identic dengan specimen kimia dalam sampel. Penambahan standar internal digunakan untuk mengkoreksi kehilangan analit selama proses preparasi sampel atau saat sampel dimasukkan. Sebelum penambahan standar, sampel diencerkan menjadi konsentrasi antara 0,1 dan $0,4 \mathrm{mg} / \mathrm{L}$. Kondisi analisis HPLC-MS/MS yang digunakan yaitu Acquity sistem UPLC1 (Waters) dengan kolom BEH C18 (2,1 x $100 \mathrm{~mm}$ ), gradien: 5-100\% asetonitril/ammonium bikarbonat (5 $\mathrm{mM}$ ) dalam 6 menit.

Hasil analisis toksikologi forensik pada sampel postmortem almarhum yaitu sebagai berikut : 
e-ISSN 2657-0815,p-ISSN 1979-1763

Asosiasi Ilmu Forensik Indonesia

64 Dewa Ayu Sri Kusuma Dewi,Ni Made Widi Astuti,Pande Made Nova Armita Sari, IMA Gelgel Wirasuta. Departemen Toksikolgi Forensik Laboratorium Toksikologi Forensik Universitas Udayana Program Studi Farmasi Fakultas Matematika dan Ilmu Pengetahuan Alam Universitas Udayana Badung 
Tabel 1. Hasil analisa toksikologi forensik pada sampel postmortem kasus agitasi [6].

\begin{tabular}{lll}
\hline \multicolumn{1}{c}{ Senyawa } & \multicolumn{1}{c}{ Matriks biologi } & Kadar yang ditemukan \\
\hline Kokain & Darah femoral & $0,0071 \mathrm{mg} / \mathrm{L}$ \\
Benzoylecgonine & Darah femoral & $0,17 \mathrm{mg} / \mathrm{L}$ \\
Methylecgonine & Darah femoral & $0,042 \mathrm{mg} / \mathrm{L}$ \\
MDMA & Darah femoral & $0,011 \mathrm{mg} / \mathrm{L}$ \\
& Darah femoral & $5,1 \mathrm{mg} / \mathrm{L}$ \\
Mephedrone & Urine & $186 \mathrm{mg} / \mathrm{L}$ \\
& Isi perut & $1,04 \mathrm{mg} / \mathrm{L}$ \\
Oxazepam & Darah femoral & Kurang dari 0,010 mg/L \\
Midazolam & Darah femoral & $0,0064 \mathrm{mg} / \mathrm{L}$ \\
Metanephrine & Darah dari jantung & Mungkin ada dengan \\
& & jumlah kecil \\
Atropin & Darah dari jantung & Mungkin ada dengan \\
& & jumlah kecil \\
Alcohol, GHB & Darah dari jantung & Tidak ditemukan \\
Obat-obatan lainnya & Darah dari jantung & Tidak ditemukan \\
& Isi perut & Tidak ditemukan \\
\hline
\end{tabular}

\begin{tabular}{|c|c|}
\hline $\begin{array}{l}\text { Adanya kokain } \\
\text { metabolitnya dan } \\
\text { (benzoylecgonine, } \\
\text { methylecgonine), MDMA, oxazepam } \\
\text { dan midazolam dalam darah } \\
\text { almarhum menegaskan penggunaan } \\
\text { atau zat tersebut. Midazolam, } \\
\text { metanephrine (metabolit epinefrin) } \\
\text { dan atropin diberikan oleh tenaga } \\
\text { medis sebagai tindakan resuitasi. } \\
\text { Namun, kadar oksazepam dan } \\
\text { midazolam terlalu rendah secara } \\
\text { signifikan untuk menyebakan } \\
\text { kematian pada pria tersebut. Kadar } \\
\text { oksazepam yang diperoleh pada } \\
\text { darah femoral yaitu kurang dari } \\
\text { 0,010 mg/L dan kadar midazolam } \\
\text { yang diperoleh pada darah femoral } \\
\text { yaitu 0,0064 mg/L. Konsentrasi } \\
\text { mephedrone paling tinggi diperoleh } \\
\text { dibandingkan senyawa lainnya. }\end{array}$ & $\begin{array}{l}\text { Konsentrasi mephedrone tertinggi } \\
\text { diperoleh pada sampel urin dengan } \\
\text { kadar } 186 \mathrm{mg} / \mathrm{L} \text {. } \\
\text { Orang ini diduga mengambil } \\
200 \mathrm{mg} \text { mephedrone secara oral dan } \\
\text { kemudian disuntikkan lagi } 3,8 \mathrm{~g} \\
\text { secara intramuskular. Secara } \\
\text { keseluruhan, hasil analisis } \\
\text { menunjukkan bahwa kadar } \\
\text { mephedrone paling tinggi ditemukan } \\
\text { pada spesimen biologis almarhum. } \\
\text { Banyaknya luka yang ditimbulkan } \\
\text { menyebabkan pria tersebut } \\
\text { kehilangan banyak darah yang } \\
\text { mungkin dapat memperburuk } \\
\text { masalah jantung dan tekanan darah } \\
\text { yang disebabkan oleh mephedrone. } \\
\text { Keadaan kemarahan seperti itu dapat } \\
\text { disebabkan oleh efek toksik dari } \\
\text { mephedrone (agresi, halusinasi, } \\
\text { psikosis). }\end{array}$ \\
\hline
\end{tabular}




\section{KESIMPULAN}

Mephedrone merupakan salah satu obat terlarang yang termasuk dalam derivate katinon sintesis yang pertama kali di sintesis pada tahun 1929. Mephedrone diklasifikasikan sebagai obat stimulan dan dikelompokkan menjadi zat psikoaktif baru (NPS). Mephdrone telah dilarang peredarannya di beberapa Negara seperti Inggris, Israel, Swedia, Denmark, Jerman, Swedia, India dan termasuk Indonesia. Penyalahgunaan mephedrone dalam dosis berlebih dapat menimbulkan agitasi hingga kematian bagi penggunanya. Adanya peningkatan kasus penyalahgunaan mephedrone, maka diperlukan suatu metode analisis toksikologi forensik yang efektif untuk mengidentifikasi metabolit senyawa mephedrone pada kasus penyalahgunaan mephedrone.

\section{DAFTAR PUSTAKA}

[1] BNN, 2013. 'Artikel'. Mengenal Katinon. viewed 26 Februari 2019,

http://www.bnn.go.id/read/artike 1/11302/mengenal-katinon

[2] BNN. 2016. Daftar Nama Zat NPS yang Sudah Teridentifikasi Di Indonesia, viewed 28 Februari 2019, http://lab.bnn.go.id/nps_alert_sy stem/12.\%20Lampiran\%20zat\% 20NPS\%20terdeteksi\%20di\%20 Indonesia.php

[3] Camilleri,A., M. R. Johnston, M. Brennan, S. Davis, D. G. Caldicott. 2010. Chemical analysis of four capsules containing the controlled substance analogues 4methylmethcathinone, 2fluoromethamphetamine, alpha phthalimidopropiophenone and N-ethylcathinone. Forensic Sci. Int. Vol. 197, pp: 59.

[4] Dargan, P.I., R. Sedefov, A. Gallegos and D.M. Wood. 2011. The pharmacology and toxicology of the synthetic cathinonemephedrone (4methylmethcathinone). Drug Testing and Analysis. 3 :454463.

[5] Gibbons, S., M. Zloh. 2010. An analysis of the 'legal high' mephedrone. Bioorg. Med. Chem. Lett.Vol.20, pp: 4135.

[6] Lusthof, K.J., R. Oosting, A. Maes, M. Verschraagen, A. Dijkhuizen, and A.G.A.Sprong. 2011. A case of extreme agitation and death after the use of mephedrone in The Netherlands. Forensic Science international. 206: 93-95.

[7] Patuwondo, M. 2018. Indonesia : Narkoba dalam Angka Tahun 2017. Jurnal Data Puslitdatin.

[8] Schifano, F., A. Albanese, S. Fergus, J.L. Stair, P. Deluca, O. Corazza, Z. Davey, J.Corkery, H. Siemann, N. Scherbaum, M. Farre, M. Torrens, Z. Demetrovics, A.H. Ghodse, P.W. Mapping, and R.R. Groups. 2011. Mephedrone (4methylmethcathinone; 'meow meow'): chemical, pharmacological and clinical issues. Psychopharmacology. 214:593-602.

[9] Wirasuta, I M. A. G. 2008. Analisis Toksikologi Forensik dan Interpretasi Temuan

66 Dewa Ayu Sri Kusuma Dewi,Ni Made Widi Astuti,Pande Made Nova Armita Sari, IMA Gelgel Wirasuta. Departemen Toksikolgi Forensik Laboratorium Toksikologi Forensik Universitas Udayana Program Studi Farmasi Fakultas Matematika dan Ilmu Pengetahuan Alam Universitas Udayana Badung Bali Indonesia 
Analisis. Indonesian Journal of Legal and Forensic Sciences, Vol. 1(1). 